\title{
Cell Proliferation in the Forebrain and Midbrain of the Adult Bullfrog, Rana catesbeiana
}

\author{
Andrea Megela Simmons ${ }^{a}$ b Seth S. Horowitz ${ }^{a, b}$ Rebecca A. Brown ${ }^{b}$ \\ Departments of a Psychology and ${ }^{b}$ Neuroscience, Brown University, Providence, R.I., USA
}

\section{Key Words}

Cell proliferation · Neurogenesis · Gliogenesis •

Amphibians · Bullfrog

\begin{abstract}
The distribution of proliferating cells in the midbrain, thalamus, and telencephalon of adult bullfrogs (Rana catesbeiana) was examined using immunohistochemistry for the thymidine analog 5-bromo-2'-deoxyuridine (BrdU) and DNA dot-blotting. At all time points examined ( 2 to 28 days postinjection), BrdU-labeled cells were located in ventricular zones at all levels of the neuraxis, but with relatively more label around the telencephalic ventricles. Labeled cells, some showing profiles indicative of dividing and migrating cells, were present in brain parenchyma from 7 to 28 days post-injection. These labeled cells were particularly numerous in the dorsal and ventral hypothalamus, preoptic area, optic tectum, and laminar and principal nuclei of the torus semicircularis, with label also present, but at qualitatively reduced levels, in thalamic and telencephalic nuclei. Doublelabel immunohistochemistry using glial and early neural markers indicated that gliogenesis and neurogenesis both occurred, with new neurons observed particularly in the hypothalamus, optic tectum, and torus semicircularis. In all brain areas, many cells not labeled with BrdU were nonetheless labeled with the early neural marker TOAD-64, indicating that these cells were postmitotic. Incorporation of DNA
\end{abstract}

measured by dot-blotting confirms the presence of DNA synthesis in the forebrain and brainstem at all time points measured. The pattern of BrdU label confirms previous experiments based on labeling with ${ }^{3} \mathrm{H}$-thymidine and proliferating cell nuclear antigen showing cell proliferation in the adult ranid brain, particularly in hypothalamic nuclei. The consistent appearance of new cells in the hypothalamus of adult frogs suggests that proliferative activity may be important in mediating reproductive behaviors in these animals.

Copyright $\odot 2007$ S. Karger AG, Basel

\section{Introduction}

The brains of many species of vertebrates naturally exhibit birth of new neurons during adulthood [review: Gould and Gross, 2002]. In mammals, this proliferative activity is concentrated in the subventricular zone of the lateral ventricles and in the dentate gyrus of the hippocampus [Altman and Das, 1965; Lois and Alvarez-Buylla, 1993]. In the brains of many non-mammalian vertebrates, cell proliferation also occurs around the telencephalic ventricular zones and in telencephalic nuclei themselves [Font et al., 2001; Zupanc, 2001; Nottebohm, 2002]. In the brains of some species of adult fish and amphibians, proliferative activity has also been observed outside of forebrain areas, both in ventricular zones and in brain parenchyma at all levels of the neuraxis. For example, in adult

\section{KARGER}

() 2007 S. Karger AG, Base

Fax +4161306 1234

E-Mail karger@karger.ch

www.karger.com
Accessible online at:

www.karger.com/bbe
Andrea M. Simmons

Department of Psychology

Box 1853, Brown University

Providence, RI 02912 (USA)

Tel. +1 401863 2283, Fax +1 401863 1300,E-Mail Andrea_Simmons@brown.edu 
zebrafish (Danio rerio), proliferating cells are found in the preoptic area of the hypothalamus, torus longitudinalis, optic tectum and cerebellum [Zupanc et al., 2005], whereas in the brown ghost fish (Apteronotus leptorhynchus), approximately $75 \%$ of all cells that are generated during adulthood are located in the cerebellum [Zupanc et al., 1996]. Similarly, in adult frogs (Rana temporaria and Rana esculenta), proliferating cells have been observed in the preoptic area [Chetverukhin and Polenov, 1993; Polenov and Chetverukhin, 1993], optic tectum [Margotta et al., 2005], and the diencephalon [Raucci et al., 2006].

Adult neurogenesis in mammals and birds has been hypothesized to facilitate or underlie learning and other forms of behavioral plasticity [Gould et al., 1999a; Nottebohm, 2002]. The more widespread proliferative activity in the brains of teleost fishes and reptiles has been attributed to the continuous growth of these brains in adulthood, which necessitates an increase in total cell number [Font et al., 2001; Zupanc, 2001]. It has also been suggested that in these species the birth of new cells might underlie regenerative activity, the capacity to replace nerve cells and to allow regrowth of nerve fibers after injury [Font et al., 1997; Byrd and Brunjes, 2001; Zupanc, 2001; Doetsch, 2003]. Greater understanding of the potential for adult cell proliferation in the brains of nonmammalian species might shed light on the more limited ability of the adult mammalian brain to generate new cells, both under normal conditions and in response to injury.

In order to further understand the phylogeny and comparative anatomy of adult neurogenesis, we examined the spatial distribution and long-term survival of newly born cells in the brain of the adult bullfrog, Rana catesbeiana. These animals show considerable cell birth in mesencephalic and rhombencephalic nuclei throughout the prolonged period of larval development and into the early postmetamorphic period [Chapman et al., 2006; Simmons et al., 2006]. There is only limited information on the extent of cell proliferation in the brains of any amphibian species during adulthood, even though adult amphibians show functional recovery after injury [Dieringer, 1995]. Previous analyses of proliferative activity in the adult Rana brain were based on the techniques of ${ }^{3} \mathrm{H}$ thymidine autoradiography [Bernocchi et al., 1990; Chetverukhin and Polenov, 1993; Polenov and Chetverukhin, 1993] and immunohistochemistry using proliferating cell nuclear antigen (PCNA) [Margotta et al., 2000, 2005; Raucci et al., 2006]. The former technique was employed only at two time periods after administration of the marker, thus limiting the data on long-term survival of newly-born cells, whereas the latter technique is not amenable to pulse-chase analysis to assess cell migration and survival. We identified the presence of mitotic cells using immunohistochemical localization of the thymidine analog, 5-bromo-2'-deoxyuridine [BrdU; Miller and Nowakowski, 1988] at five time points after administration to assess the migration and location of newly born cells. BrdU immunohistochemistry was coupled with markers for astroglia [Bignami et al., 1972] or for early postmitotic neurons [Minturn et al., 1995] to determine the phenotype of newly born cells. To complement immunohistochemical data, we employed the technique of DNA dotblot [Ueda et al., 2005] in non-sliced tissue to assess relative BrdU incorporation per quantity of DNA available for label regardless of the number of contributing cells. Our data confirm that proliferating cells in the adult bullfrog brain are not limited to telencephalic ventricular zones, but appear in telencephalic, diencephalic and mesencephalic regions at time points as long as 28 days post-BrdU injection.

\section{Materials and Methods}

\section{Animals}

Animal procedures were approved by the Brown University Institutional Animal Care and Use Committee and conform to federal guidelines. Adult male Rana catesbeiana ( $\mathrm{n}=26,200-$ $600 \mathrm{~g}$ body weight) were obtained in the months of June-July 2005 and 2006 from a commercial supplier (Dozier Lester, Duson. La., USA). Animals were housed individually in plastic terraria containing soil and water and fed live crickets ad libitum. The colony room was maintained at $28^{\circ} \mathrm{C}$ on a $12 / 12$ light/dark cycle. Experiments were performed during the months of June through September, a period of time encompassing the breeding season of these animals, and during which times they do not normally estivate.

\section{BrdU Immunohistochemistry}

Animals $(\mathrm{n}=15)$ were anesthetized by submersion in $0.6 \%$ (weight per volume, w/v) tricaine methanesulfonate (MS-222; buffered to $\mathrm{pH}$ 7; Sigma, St Louis, Mo., USA) for 15 min or until reflexes disappeared, then injected intraperitoneally with BrdU (Sigma B5002; 1000 mg/kg; pH 9) in 0.9\% w/v sterile saline. Results from preliminary experiments in which animals were administered a low dose of BrdU (100 mg/kg) showed minimal BrdU label, even around ventricular zones, at survival times of 7 days or longer. A higher dose was thus employed to maximize the amount of label at long survival times. Although BrdU has toxic and mutagenic effects when administered to pregnant or developing mammals [Kolb et al., 1999; Sekerková et al., 2004], no such effects have been observed in adult mammals administered doses as high as $600 \mathrm{mg} / \mathrm{kg}$ [Cameron and McKay, 2001]. We observed no obvious toxic effects of or behavioral abnormalities resulting from the high doses of BrdU administered to our ex- 
perimental animals. No animal died as a result of or immediately after the BrdU injection, and none exhibited any sign of nausea throughout the survival period. All animals resumed capturing live prey within $24 \mathrm{~h}$ of injection, and all continued to exhibit normal prey-catching behavior throughout the survival period.

Animals received two injections, $24 \mathrm{~h}$ apart, using sterile technique. They were allowed to survive $2,7,14,21$, or 28 days $(\mathrm{n}=3$ per group) after the initial injection. This protocol was adopted to maximize the numbers of BrdU-labeled cells at long survival time points, and to allow visualization of any migration of newly born cells from ventricular zones to brain parenchyma. Some studies of neurogenesis in adult mammals have also utilized multiple injections over periods of hours or days in order to increase the amount of label [rhesus macaques: Gould et al., 1999b; rats: Peretto et al., 2001, Olariu et al., 2007; mice: Rochefort et al., 2002], and studies in adult zebrafish have exposed animals in aquarium water mixed with BrdU for several days [ $\mathrm{Zu}$ panc et al., 2005]. The use of two injections in our study is not expected to increase the intensity of label, unless a cell goes through S-phase after the first injection and then again after the second injection. The duration of the S-phase in toads (Bufo bufo) has been estimated to be approximately $54 \mathrm{~h}$ [Chibon and Dournon, 1972, as cited in Polenov and Chetverukhin, 1993], but it has not been measured specifically in ranids. At the end of the survival period, animals were reanesthetized by immersion in $0.6 \%$ MS-222 for $30 \mathrm{~min}$ and transcardially perfused with heparinized $0.9 \% \mathrm{w} / \mathrm{v}$ saline followed by $4 \% \mathrm{w} / \mathrm{v}$ paraformaldehyde $(\mathrm{pH} 7.4)$. Brains were removed and postfixed in $4 \%$ paraformaldehyde $\left(12 \mathrm{~h}, 4^{\circ} \mathrm{C}\right)$, then embedded in $5 \% \mathrm{w} / \mathrm{v}$ agarose (ISC Bioexpress, Kaysville, Utah, USA) in saline and sliced coronally by vibratome at a thickness of $50 \mu \mathrm{m}$. Consecutive sections were placed on different gelatin-subbed glass slides, creating different slide sets so that each individual brain could undergo multiple histological treatments (BrdU alone; BrdU in combination with glial or neural markers; control, in which primary or secondary antibodies were omitted; or cresyl violet staining for identification of nuclear boundaries).

For all sections in which BrdU was to be localized, DNA strands were first denatured with room temperature (R/T) $2 \mathrm{~N}$ hydrochloric acid (Fisher Scientific, Pittsburgh, Pa., USA) for $5 \mathrm{~min}$, followed by a 2 -hour $(\mathrm{R} / \mathrm{T})$ wash in tap water. Sections were incubated in murine monoclonal anti-BrdU (1:1,000, Sigma B2531), followed by fluorescent secondary antibody (goat antimouse AlexaFluor 594, 1:750, A11005, Molecular Probes/Invitrogen, Eugene, Oreg., USA). Other sets of sections were processed using double-label immunohistochemistry for BrdU in combination with the astroglial marker, glial fibrillary acidic protein (GFAP, 1:100, Sigma G9269), or the early neural marker, TurnedOn-After-Division 64 (TOAD-64, 1:5,000, BD PharMingen San Diego, Calif., USA). These antibodies were both generated in rabbit and visualized using fluorescence (secondary antibody AlexaFluor 488, 1:750, A11008, Molecular Probes/Invitrogen). Both of these antibodies have been shown by Western blot to be recognized in Rana tissue [Simmons et al., 2006]. As controls, antibody treatments were performed with either the primary (sections from 11 brains) or secondary (sections from 4 brains) antibodies omitted. In these cases, label above the expected background was not observed.

Cell Proliferation in Adult Bullfrog Brain

\section{Image Analysis and Particle Counting}

Slides were viewed through an Olympus BX-60 microscope (Olympus, Melville, N.Y., USA) attached to a MagnaFire digital camera (Optronics, Goleta, Calif., USA). Images were captured as described previously [Chapman et al., 2006]. BrdU-positive cells fluoresced red, and GFAP or TOAD-64-positive cells fluoresced green, both against a yellow-green background. Nucleated erythrocytes and lipofuscin molecules fluoresced yellow-orange, and were easily distinguishable from bright red BrdU label. Selected sections from a sample of animals processed for BrdU/ GFAP and for BrdU/TOAD-64 were mounted in AntiFade (Molecular Probes/Invitrogen) and imaged using a Leica TCS SP2 confocal microscope system (sequential scan mode, Leica Microsystems, Bannockburn, Ill., USA). High-power z stack images were taken through each section (GFAP label, sequential scan mode, step size $0.2 \mu \mathrm{m}$, objective $100 \times$, numerical aperture 1.4 , zoom $=4$; TOAD-64 label, sequential scan mode, step size 0.5 $\mu \mathrm{m}$, objective $100 \times$, numerical aperture 1.4 , zoom $=1$ ); and viewed in orthogonal planes using Leica confocal software (Leica Microsystems).

For description of spatial extent of label, boundaries of target nuclei were determined by reference to published criteria [Nieuwenhuys and Opdam, 1976; Neary and Northcutt, 1983; Feng and Lin, 1991; Marín et al., 1997; Endepols et al., 2004] and by cresyl violet stained material obtained as part of this study. Numbers of labeled cells from selected brain areas were counted manually from actual brain sections by one of the authors, and from coded images by an observer unfamiliar with the hypothesis of this experiment. Counts of the same section area from both observers were consistent (variability $<2 \%$ ). These cell counts were used to generate schematics of distribution of label (fig. 1). Images were contrast- and brightness-adjusted and illustrations prepared using Corel PhotoPaint 11 (Corel Corp., Ontario).

\section{DNA Dot-Blot}

DNA dot-blots were used to analyze BrdU incorporation in non-vibratome-sectioned tissue samples. Similar to immunohistochemistry, BrdU is here visualized using an antibody detection method; however, the dot-blot technique quantifies how much BrdU nucleotide is incorporated per quantity of DNA available for label, rather than indicating how many cells in a tissue sample are individually labeled with BrdU. Moreover, the technique utilizes a purification step to maximize recovery of high-molecularweight DNA and to minimize recovery of RNA prior to 'dotting' on the membrane. This allows confirmation that the results obtained through immunohistochemistry are due to BrdU detected in DNA strands, rather than from RNA incorporation of the BrdU molecule.

Dot-blots were obtained from brain tissue (obex through rostral tectum; thalamus and telencephalon) of 10 animals at time points of 2, 7, 14, 21 and 28 days post-BrdU injection (2 animals per time point). Animals were given two injections of BrdU, $24 \mathrm{~h}$ apart, as described above. One control animal was injected with sterile saline in a volume equal to that of BrdU injections in experimental animals, and euthanized after 2 days. DNA was extracted using GenElute Mammalian Genomic DNA Miniprep Kit (Sigma). DNA concentration and quality were determined by OD260/280 ratios by UV spectrophotometry. 100 ng of DNA from each animal was dotted onto a nitrocellulose membrane (BioTrace NT, Pall Gelman, East Hills, N.Y., USA) and baked 


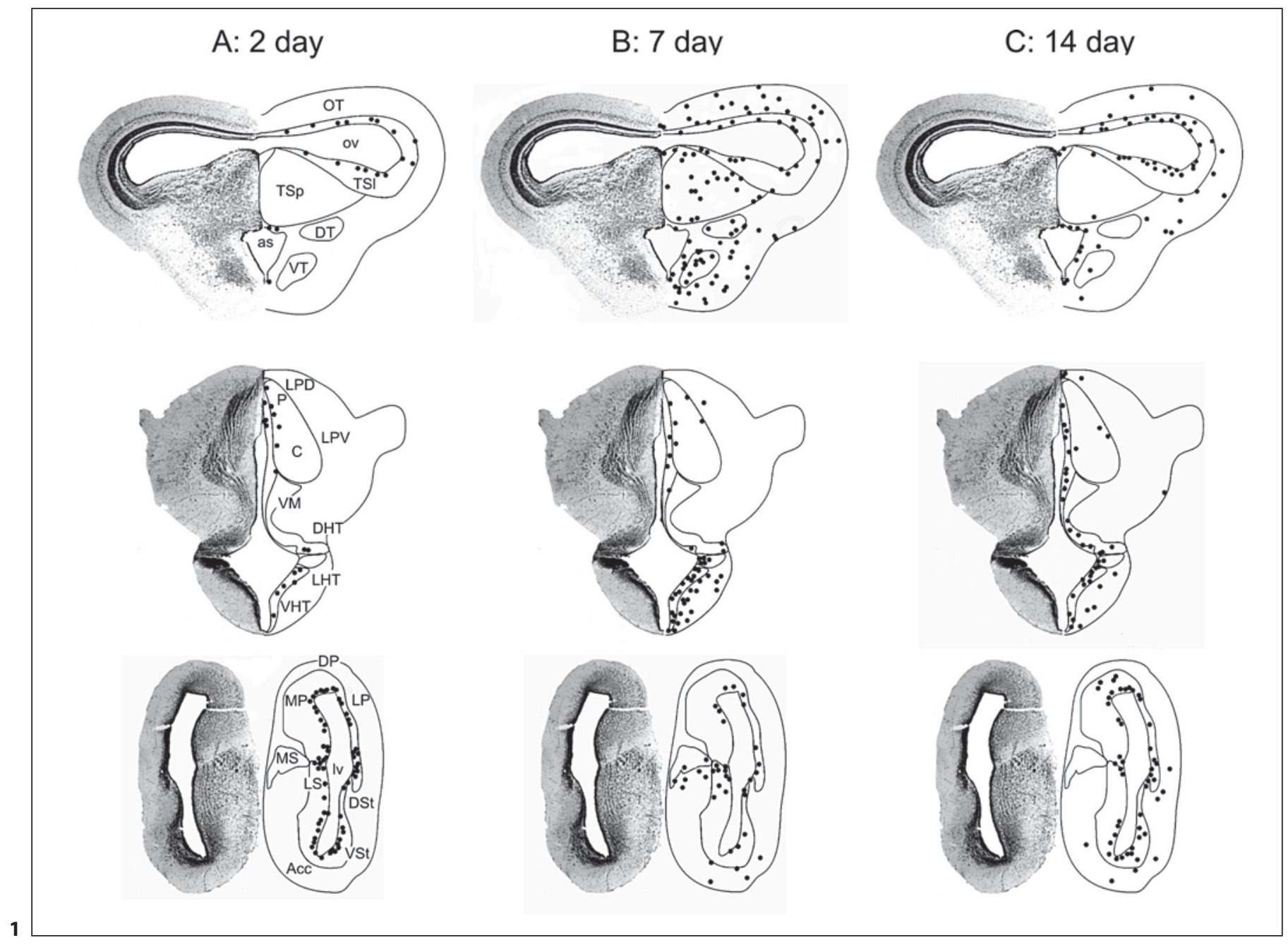

\section{Abbreviations used in fig. 1}

\begin{tabular}{llll}
\hline Acc & nucleus accumbens & lv & lateral ventricle \\
as & aqueduct of Sylvius & MP & medial pallium \\
C & central nucleus of the thalamus & MS & medial septum \\
DHT & dorsal hypothalamus & OT & optic tectum \\
DP & dorsal pallium & ov & optic ventricle \\
DSt & dorsal striatum & P & posterior nucleus of the thalamus \\
DT & dorsal tegmentum & TSl & laminar nucleus of the torus semicircularis \\
LHT & lateral hypothalamus & TSp & principal nucleus of the torus semicircularis \\
LP & lateral pallium & VHT & ventral hypothalamus \\
LPD & lateral posterior dorsal thalamic nucleus & VM & ventromedial nucleus of the thalamus \\
LPV & lateral posterior ventral thalamic nucleus & VSt & ventral striatum \\
LS & lateral septum & VT & ventral tegmentum
\end{tabular}




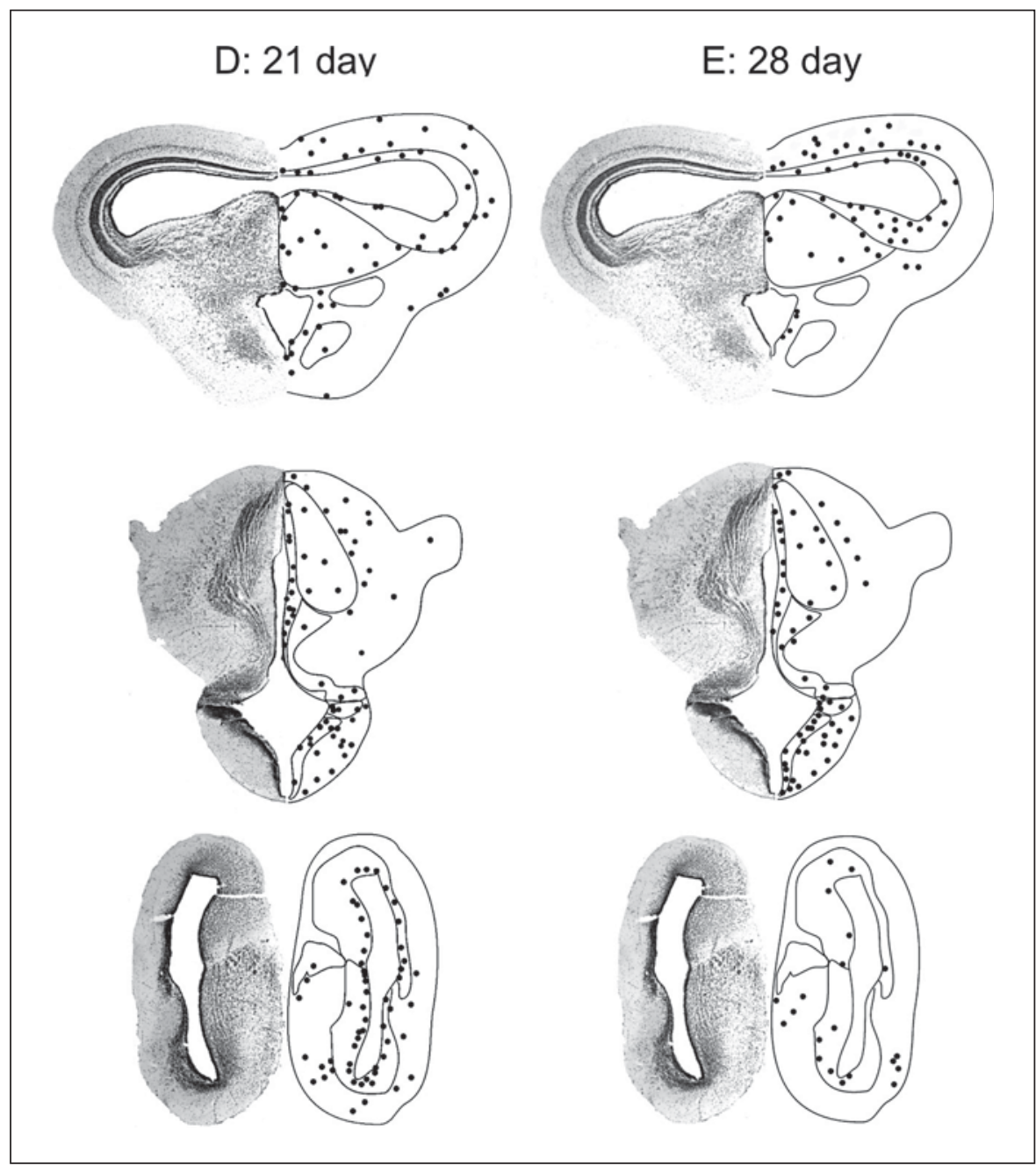

Fig. 1. Schematic diagrams showing the distribution of BrdU-labeled cells (black filled circles) in sections from midbrain (top row), thalamus (center row), and forebrain (bottom row) of sample adult male bullfrogs. Dark circles are the mean cell count averaged over three non-consecutive sections from an individual animal. A 2-day survival time. B 7-day survival time. C 14-day survival time. D 21-day survival time. E 28-day survival time. Left half of images are derived from cresyl violet-stained 50- $\mu \mathrm{m}$-thick coronal sections; right half of images are line drawings based on an atlas developed in our laboratory. onto the membrane at $80^{\circ} \mathrm{C}$ for $3 \mathrm{~h}$. Thalamic and telencephalic tissue sources were combined, and dotted onto separate membranes from brainstem tissue. Tissue from each animal was dotted two separate times on the same membrane, to serve as an internal control. Endogenous peroxidases were quenched with $3 \%$ hydrogen peroxidase $(15 \mathrm{~min} \mathrm{R} / \mathrm{T})$. The membranes were incubated with anti-BrdU antibody (1:1,000 dilution) for $2 \mathrm{~h}(\mathrm{R} /$ $\mathrm{T})$, washed, and then incubated for $2 \mathrm{~h}(\mathrm{R} / \mathrm{T})$ with peroxidaseconjugated goat anti-mouse IgG antibody (1:750 dilution, Sigma A4416) and reacted with diaminobenzidine (Vector Laboratories, Burlingame, Calif., USA). The resulting dot-blots were digitally scanned and signal intensities measured, averaged over the four dots from the two animals per time point, and normalized with respect to intensities of dot-blots from the control animal using the integrated density function in ImageJ software (freeware from NIH). Normalized densities at different time points were graphed using SigmaPlot (Jandel, Point Richmond, Calif., USA).

\section{Results}

\section{Immunohistochemistry: General Trends}

BrdU-labeled cells were observed in the mesencephalon, diencephalon, and telencephalon at all survival time points after initial BrdU injection, but the numbers and locations of labeled cells varied with survival time. Only minimal label was observed in the medulla itself or around the fourth ventricle at the level of the medulla at any survival time point, so data from these areas are not presented here. Figure 1 shows schematics of brain sections through the midbrain, thalamus, and telencephalon illustrating the calculated number and position of BrdUlabeled cells at survival times of 2-28 days. Data in the schematics are based on the mean number of labeled cells from three non-consecutive sections of that particular brain area from the animal exhibiting the heaviest label 


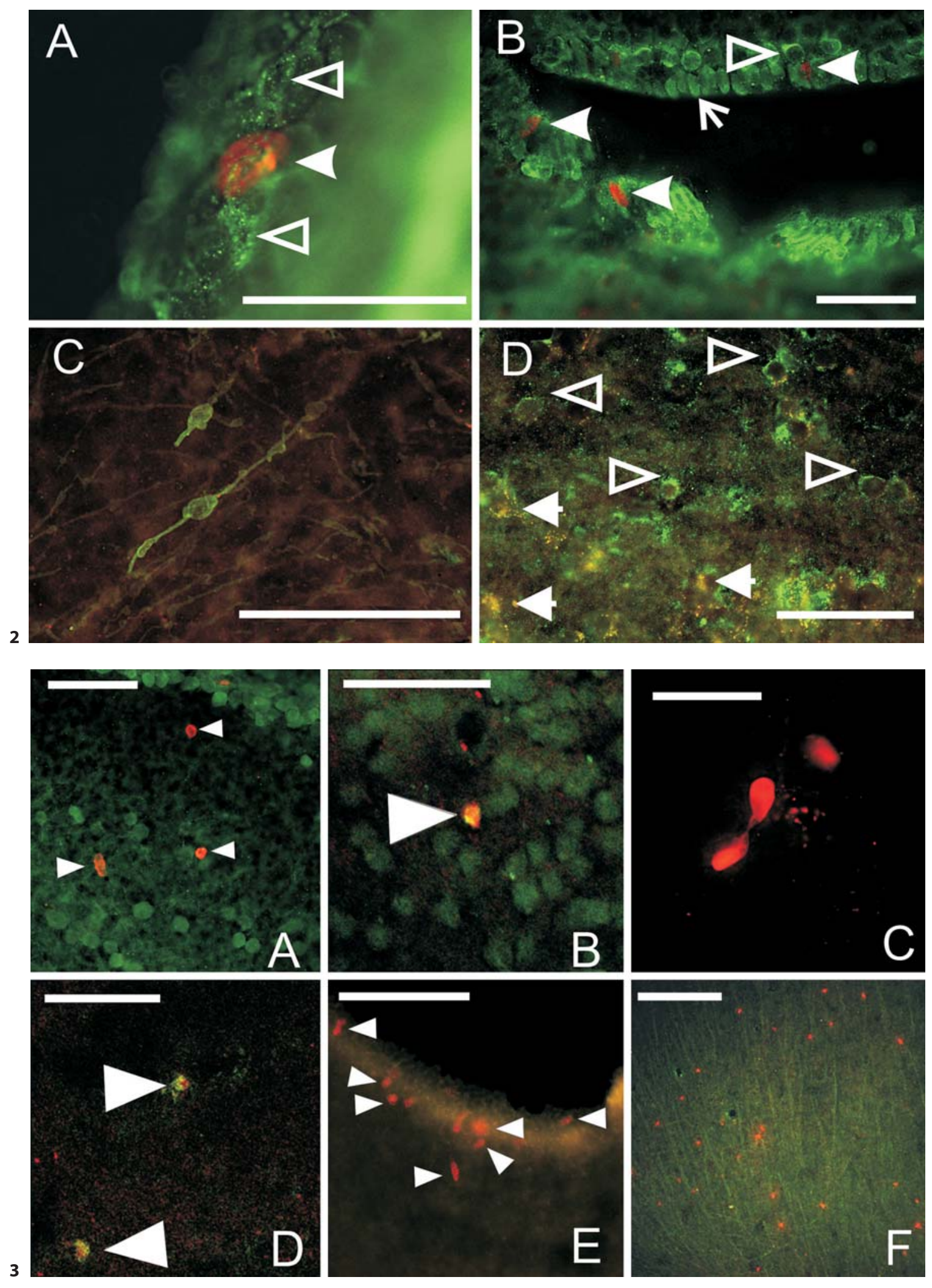


at that survival time. There was minimal inter-individual variability in the location of labeled cells at the same time point, although the actual numbers of labeled cells could vary between individuals, particularly at long time points. The data show that, after 2-day survival (fig. 1A), BrdU-labeled cells are concentrated in the ventricular zones, with particularly heavy label along the lateral ventricles in the telencephalon. BrdU-labeled cells are evident outside the ventricular zones at 7, 14, 21, and 28 days (fig. 1B-E) survival. Labeled cells are particularly numerous in the preoptic area (not shown), dorsal and ventral hypothalamus, optic tectum, and torus semicircularis (TS), and are also present, but to a lesser extent and with more inter-individual variability in numbers of labeled cells, in the medial septum, lateral septum, ventral striatum, nucleus accumbens, posterior commissure, and posterior and central thalamic nuclei. Generally, the relative numbers of labeled cells are similar at all time points, indicating that newly proliferating cells can survive for as long as 28 days.

As shown in figure 2, GFAP- (fig. 2A, B) and TOAD64- (fig. 2C, D) labeled cells and processes are also visible

Fig. 2. Distribution of GFAP and TOAD-64 label. A Discrete GFAP- (green, hollow arrowheads) labeled cells and BrdU- (red, solid arrowhead) labeled cell in the ventricular zone of the thalamus 7 days post-BrdU injection. Note that GFAP-labeled fibers appear to encircle non-labeled, presumably ependymal cells. B GFAP- (green, hollow arrowheads) and BrdU- (red, solid arrowheads) labeled cells 2 days post-BrdU injection in the telencephalic ventricular zone. Some GFAP-labeled cells (arrow) directly abut the lateral ventricle. C TOAD-64-(green) labeled cells and processes in the ventral hypothalamus 14 days post-BrdU injection. D TOAD-64-labeled cells (green, hollow arrowheads) in the principal nucleus of the TS 14 days post-BrdU injection. Three cells (yellow, arrowheads) double-labeled with BrdU and TOAD-64 are out of the plane of focus of the section. For all images, medial is to the left, dorsal is up. Scale bars $=50 \mu \mathrm{m}$.

Fig. 3. BrdU label and double label in various regions of the adult brain. A Discrete label of BrdU- (red, solid white arrowheads) and GFAP- (green) labeled cells in the laminar nucleus of the TS 7 days post-BrdU injection. B Confocal image of BrdU/GFAP-doublelabeled cell (solid white arrow) in the ventral hypothalamus 7 days post-BrdU injection. C Dividing BrdU-labeled cells (red) in the posterior nucleus of the thalamus at 14 days post-BrdU injection. D Confocal image of BrdU/TOAD-64-double-labeled cells (solid white arrowheads) in the posterior nucleus of the thalamus 14 days post-BrdU injection. E BrdU-labeled cells (red) around the ventral portion of the telencephalic ventricle (region of the nucleus accumbens) 21 days post-BrdU injection. F BrdU-labeled cells (red) and GFAP-labeled fibers (green) in the optic tectum 28 days post-BrdU injection. For all images, medial is to the left and dorsal is up. Scale bars $=50 \mu \mathrm{m}$.

Cell Proliferation in Adult Bullfrog Brain at all time points. In the ventricular zones, GFAP-labeled processes could be seen extending around and between unlabeled, presumably ependymal, cells (fig. 2A, B). GFAP-labeled cells often abut the ventricle directly, particularly in the lateral ventricles (fig. 2B). In either case, GFAP-labeled cells and processes are evident in close proximity to BrdU-labeled cells (fig. 2A, B, 3E). TOAD64-labeled cells are located outside of, or on the border of, the ventricular zones (fig. 2C, D, 3D); none were observed abutting the ventricles themselves. Some of these cells (fig. 2C) show profiles characteristic of migrating neurons, with label of both cell bodies and processes [Minturn et al., 1995]. Cells double-labeled with BrdU and either GFAP or TOAD-64 (fig. 3B, D) are observed beginning at the 7-day survival time point and extending to the 28-day time point. These double-labeled cells are exclusively located in parenchyma, outside the ventricular zones. Qualitatively, the relative numbers of double-labeled cells varied between brain areas and across survival time points, but the relative proportion of cells double-labeled with GFAP or with TOAD-64 at any one time point was similar. Proportions of double-labeled cells in the brain areas that were quantitatively censused ranged from 0 to $18 \%$.

\section{2-Day Survival}

Data from the three animals studied at this time point are consistent. BrdU-labeled cells are concentrated around the lateral ventricles, both in dorsal (pallial) and ventral (striatal) regions (fig. 1A, 2B). Labeled cells are also observed, but in smaller numbers, around the third and fourth ventricles at the level of the thalamus and hypothalamus, around the tectal ventricle, in the ventricular layers bordering the optic tectum and the laminar nucleus of the TS (TSl), and around the aqueduct of Sylvius. No BrdU-labeled cells are visible in the brain parenchyma. No cells double-labeled with BrdU and either GFAP or TOAD-64 are seen in any brain area.

\section{7-Day Survival}

At 7 days post-injection (fig. 1B), BrdU-positive cells are again visible around the ventricular zones at all levels of the telencephalon, diencephalon (fig. 2A), and mesencephalon, with most labeled cells located around the lateral ventricles and fewest around the fourth ventricle. In all three animals, considerable numbers of BrdU-labeled cells are observed in the optic tectum, laminar (fig. 3A) and principal nuclei (TSp) of the TS, medial preoptic area, and dorsal and ventral (fig. 3B) hypothalamus, particularly at more caudal levels. Consistently less label is seen in the medial septum, lateral preoptic area, central and lateral thalamic 


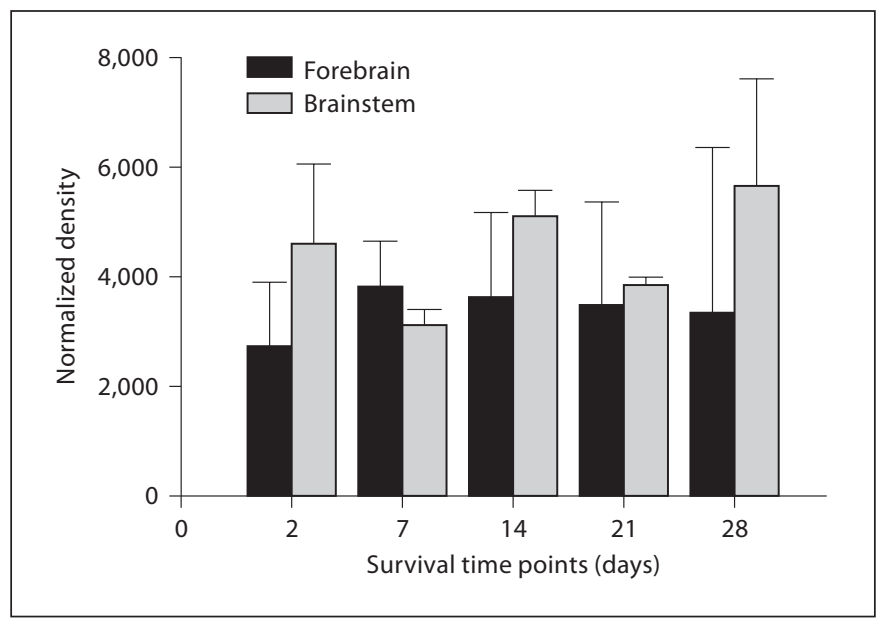

Fig. 4. Comparison of dot-blot data showing normalized densitometry for blots derived from forebrain tissue (thalamus and telencephalon, black bars) and brainstem tissue (midbrain and hindbrain, gray bars) at 2, 7, 14, 21, and 28 days post-BrdU injection. Error bars are standard deviations.

nuclei, posterior commissure, and tegmentum. There is minimal label in the pallium and dorsal striatum. About $6 \%$ of the BrdU-labeled cells in the thalamus and hypothalamus (fig. 3B) were double-labeled with GFAP.

\section{4-Day Survival}

Results at 14 days survival (fig. 1C) are similar to those at 7 days. Ventricular label is heavy around the lateral ventricles, becoming sparser, although still considerable, toward the fourth ventricle. In the telencephalon, most BrdU label remains concentrated around the ventricles, with fewer labeled cells observed in the dorsal pallium and striatum. Sections from all three animals show consistent label in the dorsal and ventral hypothalamus, medial preoptic area, posterior thalamus (fig. 3D), posterior commissure, optic tectum, and laminar and principal nuclei of the TS. Cell profiles consistent with migrating neurons are visible, particularly in the thalamic nuclei (fig. 3C), hypothalamus, optic tectum, and TS. The proportions of cells double-labeled with BrdU and TOAD-64 in one animal were $13 \%$ (thalamic nuclei; fig. 3C), $18 \%$ (hypothalamus) and 14\% (TS).

\section{1-Day Survival}

Three animals were studied at this time point, but the numbers of labeled cells showed more inter-individual variability than observed at either 7 or 14 days. All animals show considerable, consistent label in ventricular zones (fig. 1D, 3E), but with fewer cells around the lateral ventricles than observed at earlier time points. Overall, the numbers of labeled cells in these brain areas are similar to those observed at the 14-day survival time point. In the thalamus of one animal, approximately $11 \%$ and $14 \%$ of BrdU-labeled cells are double-labeled with either GFAP or TOAD-64, respectively, whereas in the midbrain (optic tectum and TS combined) these proportions are 14 and $15 \%$, respectively.

\section{8-Day Survival}

Even at a survival time of 28 days, bright BrdU label is still observed in many brain areas (fig. 1E). BrdU-labeled cells are observed both in ventricular zones and in brain parenchyma, but in all animals, there is less label in the telencephalon, both around ventricular zones and in telencephalic nuclei themselves, than at earlier time points. One animal shows considerable label in the dorsal and ventral hypothalamus, optic tectum (fig. 3F) and TS, at a level similar to that observed in the most heavily labeled sections from these brain areas at the 7- and 21-day time points. BrdU-labeled cells in the optic tectum seem to be closely associated with GFAP-labeled fibers (fig. 3F), suggesting that newly proliferating cells are migrating along radial glia. In one animal, $8 \%$ of BrdU-labeled cells in the thalamus and $18 \%$ of cells in the hypothalamus are double-labeled with TOAD-64.

\section{DNA Dot-Blots}

Plots of normalized integrated density of DNA dotblots at five time points after BrdU injection are shown in figure 4 . The relative amount of BrdU incorporation measured by this technique varies across survival time for both the forebrain (thalamus and telencephalon) and brainstem (midbrain and hindbrain) tissue, but the pattern of variation is qualitatively different in the two kinds of tissue. In the forebrain, density values are lowest at 2 days but increase at 7 days, remaining at that level up to 28 days. The lower density at 2 days is consistent with the immunohistochemical data showing that DNA synthesis is restricted to the ventricular zones at this time point, but is present in brain parenchyma at longer time points. Standard deviations are larger at 28 days, consistent with the greater inter-individual variability seen in the immunohistochemical results at this time point. Brainstem data show relatively greater variability across survival time. Although the density values for these data appear absolutely larger than those for the forebrain data, values cannot be compared directly because the tissue samples from these different brain re- 
gions were dotted onto separate membranes, and thus background levels are not similar. The brainstem tissue contains both midbrain and hindbrain areas, and thus cannot be compared directly to immunohistochemical results, which do not include counts from hindbrain nuclei. In spite of these differences, it is clear from these data that DNA synthesis persists in adult brain tissue up to 28 days post-BrdU injection.

\section{Discussion}

This study is the first to show cell proliferation in the brain of an adult ranid frog using the techniques of BrdU immunohistochemistry and DNA dot-blotting. Results of the immunohistochemical experiments show the presence of BrdU-labeled cells around the ventricles, most heavily around the lateral ventricles in the telencephalon and less apparent around the aqueduct of Sylvius, at time points of 2-28 days post-BrdU injection. At 7-28 days survival, profiles indicative of migrating and of dividing cells are observed in many brain areas, suggesting that newly born cells are migrating out of the ventricular zones. For example, in the midbrain, the distribution of BrdU-labeled cells broadens from being restricted to the ventricular zones at 2 days post-BrdU injection to encompass even very dorsal (optic tectum) and lateral (TS) regions at 28 days post-injection. The observations that BrdU label is still bright and, in some animals, quite extensive in some brain areas 28 days after BrdU administration suggest that mitosis is still occurring and that proliferating cells can survive for long time periods. The persistence of BrdU label in both spatial extent and in relative cell numbers at extended survival times is consistent with patterns of BrdU label seen in the brains of two species of adult fish [Zupanc et al., 1996, 2005].

Results from the DNA dot-blots confirm the continued presence of DNA synthesis in adult ranid brain tissue at long survival time points. The data show that, qualitatively, the relative amount of BrdU incorporation, measured by dot-blot using a non-fluorescent detection method, does not vary across survival time, consistent with the relatively stable cell counts derived from our fluorescently-conjugated immunohistochemical detection method. This consistency in the pattern of results between the two techniques indicates that the threshold criteria used to identify BrdU-labeled cells in sliced tissue sections were neither too high nor too low. This is important because manual identification of labeled cells can be compromised by dilution of label, and by the dif- ficulty of identifying individual labeled cells in relatively thickly sliced tissue. The dot-blot technique is useful for studies of cell proliferation because it does not require time-consuming tissue sectioning or processing; as such, it is a useful tool when cellular resolution is not necessary. On the other hand, this technique cannot provide information on regional distribution of DNA synthesis within the particular tissue studied, and cannot address the issue of whether new neurons specifically are being born. Nonetheless, the similarity in results between dotblots and immunohistochemistry provides strong evidence of continued cell proliferation in the adult bullfrog brain.

Our immunohistochemical data show interesting patterns of distribution of BrdU-labeled cells. One observation of note is that BrdU-labeled cells in the telencephalon remain clustered around the lateral ventricles, even at 28 days survival. Although there is evidence of migration of cells from the ventricles into telencephalic nuclei themselves, numbers of labeled cells in telencephalic nuclei are relatively low compared to numbers in the ventricular zone. Outside the ventricular zone, labeled cells are scattered in the medial septum, lateral septum, ventral striatum and nucleus accumbens. The biological relevance of this pattern of distribution is an interesting avenue for further exploration. The striatum in anurans is believed to be homologous with the striatum of mammals [Endepols et al., 2004], a brain area, in adult rabbits, in which neurogenesis has recently been reported to occur [Luzzati et al., 2006]. In ranids, the striatum and the nucleus accumbens project to the TS and to the posterior nucleus of the thalamus, brain regions important for processing species-specific advertisement calls [Feng and Schellart, 1999]. There are few, but conflicting, functional data available on the role of these two telencephalic areas in mediating either auditory perception or vocal behavior in frogs [Mudry and Capranica, 1980; Schmidt, 1988; Walkowiak et al., 1999]. The sparse distribution of BrdU-labeled cells in the medial pallium, the presumed homolog of the mammalian hippocampus [Northcutt and Ronan, 1992], was not expected, given the observations of considerable cell proliferation in presumed homologous areas of the telencephalon in zebrafish [Zupanc et al., 2005] and in reptiles [Font et al., 2001]. We did observe, on the other hand, considerable cell proliferation in the ventral hypothalamus and the preoptic area, brain areas important for reproductive behaviors and that receive projections from auditory nuclei in the thalamus and midbrain [Allison and Wilczynski, 1991; Marín et al., 1997]. 
BrdU label was also widespread in both the laminar and principal nuclei of the TS, and present, but relatively sparser, in the posterior thalamus. These observations suggest that cell proliferation in adulthood might be important for mediating perception of advertisement calls in frogs, a behavior pattern reflecting reproductive readiness in both males and females. We also noted considerable BrdU label around the tectal ventricle and in the optic tectum itself. In both the goldfish Carassius auratus [Raymond and Easter, 1983] and the zebrafish [Zupanc et al., 2005], proliferating cells at tectal levels of the brain are mostly limited to the tectal ventricular zone and are not widely seen in the tectum itself. The biological significance of cell proliferation in the adult bullfrog optic tectum is yet to be explored.

The widespread neurogenesis in adult fishes and reptiles has been related to the continual growth of the brains of these animals during adulthood [Font et al., 2001; Zupanc, 2001]. Whether the adult bullfrog brain similarly continues to grow throughout adulthood as a function of the addition of new neurons is not known. We observed no relationship between body weight and medial-lateral extent of the optic tectum in the brains in our sample, but these data are insufficient to correlate body and brain size.

Results of our double-labeling experiments suggest that both neurogenesis and gliogenesis occurs in the adult bullfrog brain. Yet, in some brain areas (optic tectum, TS, hypothalamus, thalamus), we identified relatively few (maximum of about $18 \%$ of the total labeled) cells double-labeled with BrdU and with either GFAP or TOAD-64. Similarly, Luzzati et al. [2006] observed that only about one-third of the proliferating cells in the rabbit striatum expressed either a glial or a mature neural phenotype. These authors suggested that birth of new cells occurs in the striatum but that these cells do not survive. Simmons et al. [2006] estimated the percentages of double-labeled cells in the TS of recently metamorphosed froglets surviving 30 days post-BrdU injection to be approximately $20 \%$ (BrdU-GFAP) and 10\% (BrdU-TOAD-64). These estimates in the froglet TS are within the same general range as those obtained in the adult TS at a similar survival time [this study]. The estimated percentage of new neurons is, on the other hand, less than calculated from immunohistochemistry for the neural marker protein $\mathrm{Hu}$ in the adult zebrafish brain [48-53\% at survival time points of 270 and 279 days; Zupanc et al., 2005]. The lower percentage of new neurons in the adult bullfrog brain might indicate greater death of newly born cells; alternatively, differences in results might reflect species differences or differences in the antibodies used. We further note that the presence of dou- ble label can only be verified through use of confocal microscopy. Confocal microscopy was performed on only selected sections in selected animals (one per time point), so our data can only be taken as estimates.

We did observe the presence of considerable numbers of cells labeled with TOAD- 64 but not with BrdU. TOAD64 is a neural-specific protein expressed in growth cones, cell bodies, and processes of early postmitotic neurons [Minturn et al., 1995]. In the rat cortex, this protein is expressed only transiently during development, and is 'almost undetectable' in the adult. In the bullfrog brainstem, TOAD-64 is also expressed during development [Chapman et al., 2006; Simmons et al., 2006], but, in contrast to the rat cortex, it remains detectable in adults [this study]. This continued presence of TOAD-64 label lends support to the contention that the adult bullfrog brain contains early postmitotic neurons. The relatively low numbers of double-labeled BrdU-TOAD-64 cells that we observed suggest that there might be populations of cells in the bullfrog's brain that are postmitotic but not yet fully differentiated. The functions of these incompletely differentiated cells are not known. It is possible that this population of immature neurons underlies the ability of the frog's brain to undergo regeneration after injury, as it has been noted that injury can induce differentiation into both astroglia [Faijerson et al., 2006] and new neurons [Tseng et al., 2006] in vitro.

Astroglia (radial glia and astrocytes) might act as stem cells during embryonic development as well as in the adult [reviews: García-Verdugo et al., 2002; Doetsch, 2003]. In the adult mammalian brain, the walls of the ventricles are lined with ependymal cells, whereas GFAPpositive cells (astrocytes) are located more ventrally, in the subventricular zone. Some of these astrocytes extend processes between the ependymal cells to directly contact the ventricle. In contrast, in the brains of birds and reptiles, there is no clear distinction between an ependymal layer and a subventricular zone. In these brains, GFAPpositive cells can directly abut the ventricles, whereas others extend processes around unlabeled, presumably ependymal, cells, in the typical mammalian fashion [García-Verdugo et al., 2002; Doetsch, 2003]. Our results showing the distribution of GFAP label in the adult bullfrog ventricular zone (fig. 2A, B) are consistent with those seen in the ventricular zones of birds and reptiles.

Our data confirm and extend previous reports of cell proliferation in the adult ranid brain based on other techniques $\left[{ }^{3} \mathrm{H}\right.$-thymidine incorporation: Bernocchi et al., 1990; Chetverukhin and Polenov, 1993; Polenov and Chetverukhin, 1993; immunohistochemistry for PCNA: 
Margotta et al., 2000, 2005; Raucci et al., 2006]. The consistencies between these studies are important because data are based on different techniques and on different ranid species; together, the combined results confirm that cell proliferation is present in the brains of adult ranid frogs, even in areas outside of the telencephalic ventricular zones and the forebrain itself. These studies all agree that considerable numbers of proliferating cells are found in ventricular zones at all levels of the neuraxis. The present data and those of Bernocchi et al. [1990] and Raucci et al. [2006] all show that considerably fewer proliferating cells are found around the fourth ventricle than around the lateral, third and tectal ventricles. Both Bernocchi et al. [1990] and Chetverukhin and Polenov [1993] observed few ${ }^{3} \mathrm{H}$-thymidine-labeled cells in brain parenchyma $2 \mathrm{~h}$ after treatment; we observed no BrdU-labeled cells outside of the ventricular zones at 2 days survival time, suggesting that migration does not occur at these short time periods. Our data showing BrdU-label in the preoptic area and in the hypothalamus 28 days post-injection is consistent with those of Polenov and Chetverukhin [1993] showing considerable numbers of ${ }^{3} \mathrm{H}$-thymidine-labeled cells in the preoptic area 30 days post-thymidine administration and with data of Raucci et al. [2006] of a 'conspicuous concentration' of PCNA-labeled cells in these areas. Our data are also consistent with those of Raucci et al. [2006] in showing the presence of proliferating cells in the thalamic nuclei. In contrast to their results, but consistent with the results of Margotta et al. [2005], we observed BrdU-labeled cells in the optic tectum and in the laminar and principal nuclei of the TS.

Some of the differences in results between these studies could reflect differences in results of PCNA and BrdU labeling, particularly when BrdU label is assessed at long time points post-injection. Studies directly comparing the presence of PCNA and BrdU label show that these techniques produce consistent labeling patterns at short time points ( 2 and $26 \mathrm{~h}$ post-BrdU injection) and when multiple BrdU injections are administered [adult rodent rostral migratory stream, Valero et al., 2005], but results at longer time points were not compared. Photoperiod or seasonal variables might also influence the degree of cell proliferation [Chetverukhin and Polenov, 1993; Ramirez et al., 1997] and thus possibly contribute to differences in results. Raucci et al. [2006] used animals collected in June, but date of euthanasia was not specified; Margotta et al. [2000] used animals both collected and euthanized in November; and we used animals that arrived in the laboratory in June-July and were euthanized by September. None of these studies systematically examined seasonal variation in cell prolif- eration, although seasonal variation of mitosis has been observed in amphibian lens and corneal epithelium [Rothstein et al., 1975]. Differences between results could also be due to the fact that data are based on animals that were not laboratory-raised, but were either wild-caught or raised by suppliers, and thus experienced differences in such conditions as diet, predation threat, and presence of conspecifics, among others. These and other differences in physical or social environment might affect cell proliferation in anurans in a manner similar to the experiential modulation of neurogenesis in adult mammals [Kempermann et al., 1998; Rochefort et al., 2002].

Methodological issues with the use of BrdU for studies of cell proliferation have been discussed previously [Gould and Gross, 2002; Cooper-Kuhn and Kuhn, 2002; Rakic, 2002; Chapman et al., 2006]. Of particular concern in this study is the high dose of BrdU that was administered. We noted no toxic effects or obvious behavioral abnormalities in our animals as a consequence of the injection, and toxic effects have not been observed in adult mammals also administered high doses [Cameron and McKay, 2001]. In preliminary experiments, we noted only minimal label at long time points after administration of a low dose of $100 \mathrm{mg} / \mathrm{kg}$; however, future studies should directly compare patterns of label after low and high doses to more accurately assess the influence of dose on amount of cell proliferation. Another methodological issue of concern is our use of two injections of BrdU for labeling proliferating cells. This was done to increase the amount of label. Multiple injections have also been employed in studies of cell proliferation in mammals to increase the numbers of labeled cells [Gould et al., 1999b; Peretto et al., 2001; Rochefort et al., 2002; Valero et al., 2005; Luzatti et al., 2006; Olariu et al., 2007]. It has been argued, however, that multiple injections of BrdU might intensify the labeling of low levels of normal DNA turnover and thus yield false-positive results [Rakic, 2002]. If our results reflect merely a process of normal DNA turnover than actual proliferation of new cells, then it is difficult to understand why the presence of BrdU label varies between different brain regions consistent with results obtained with PCNA immunohistochemistry [Margotta et al., 2000, 2005; Raucci et al., 2006] and after single injections of ${ }^{3} \mathrm{H}$-thymidine [Bernocchi et al., 1990; Chetverukhin and Polenov, 1993; Polenov and Chetverukhin, 1993]. Our previous analysis of cell proliferation in the brainstem of bullfrog tadpoles indicated that numbers and spatial distribution of proliferating cells at short time points were consistent when the data were normalized for number of injections [Chapman et al., 2006; Simmons et 
al., 2006]. We emphasize that our results do not necessarily reflect the absolute numbers of mitotic cells present at any particular survival time. They do, however, allow comparison of relative numbers of labeled cells between different survival periods and identification of brain areas where cell proliferation might occur.

\section{Acknowledgements}

This research was supported by NIH grant R01 DC05257 (A. M.S.) and by an undergraduate fellowship from the Rhode Island Space Grant Consortium (R.A.B.). We thank Judith A. Chapman, Leslie H. Tanyu and Joshua L. Weinstein for assistance.

\section{References}

Allison JD, Wilczynski W (1991) Thalamic and midbrain auditory projections to the preoptic area and ventral hypothalamus in the green treefrog (Hyla cinerea). Brain Behav Evol 38:322-331.

-Altman J, Das GD (1965) Autoradiographic and histological evidence of postnatal hippocampal neurogenesis in rats. J Comp Neurol 124:319-336.

- Bernocchi G, Scherini E, Giacometti S, Mareš V (1990) Premitotic DNA synthesis in the brain of the adult frog (Rana esculenta $\mathrm{L}$.): an autoradiographic $3 \mathrm{H}$-thymidine study. Anat Rec 228:461-470.

-Bignami A, Eng LF, Dahl D, Uyeda CT (1972) Localization of the glial fibrillary acidic protein in astrocytes by immunofluorescence. Brain Res 43:429-435.

-Byrd CA, Brunjes PC (2001) Neurogenesis in the olfactory bulb of adult zebrafish. Neuroscience 105:793-801.

-Cameron HA, McKay RDG (2001) Adult neurogenesis produces a large pool of new granule cells in the dentate gyrus. J Comp Neurol 435:406-417.

-Chapman JA, Weinstein JL, Simmons AM (2006) Cell proliferation in the Rana catesbeiana auditory medulla over metamorphic development. J Neurobiol 66:115-133.

-Chetverukhin VK, Polenov AL (1993) Ultrastructural radioautographic analysis of neurogenesis in the hypothalamus of the adult frog, Rana temporaria, with special reference to physiological regeneration of the preoptic nucleus. I. Ventricular zone cell proliferation. Cell Tissue Res 271:341-350.

-Cooper-Kuhn CM, Kuhn HG (2002) Is it all DNA repair? Methodological considerations for detecting neurogenesis in the adult brain. Brain Res Dev Brain Res 134:13-21.

- Dieringer N (1995) 'Vestibular compensation': Neural plasticity and its relations to functional recovery after labyrinthine lesions in frogs and other vertebrates. Prog Neurobiol 46:97-129.

Doetsch F (2003) The glial identity of neural stem cells. Nat Neurosci 6:1127-1134.

- Endepols H, Roden K, Luksch H, Dicke U, Walkowiak W (2004) Dorsal striatopallidal system in anurans. J Comp Neurol 468:299310.
Faijerson J, Tinsley RB, Aprico K, Thorsell A, Nodin C, Nilsson M, Blomstrand F, Eriksson PS (2006) Reactive astrogliosis induces astrocytic differentiation of adult neural stem/ progenitor cells in vitro. J Neurosci Res 84: 1415-1424.

Feng AS, Lin W (1991) Differential innervation patterns of three divisions of frog auditory midbrain (torus semicircularis). J Comp Neurol 306:613-630.

Feng AS, Schellart N (1999) Central auditory processing in fishes and amphibians. In Comparative Hearing: Fish and Amphibians (Fay RR, Popper AN, eds), pp 218-268. New York: Springer-Verlag.

Font E, Desfilis E, Pérez-Cañellas M, Alcántara S, García-Verdugo JM (1997) 3-Acetylpyridine-induced degeneration and regeneration in the adult lizard brain: a qualitative and quantitative analysis. Brain Res 754: 245-259.

- Font E, Desfilis E, Pérez-Cañellas MM, GarcíaVerdugo JM (2001) Neurogenesis and neuronal regeneration in the adult reptilian brain. Brain Behav Evol 58:276-295.

-García-Verdugo JM, Ferrón S, Flames N, Collado L, Desfilis E, Font E (2002) The proliferative ventricular zone in adult vertebrates: A comparative study using reptiles, birds, and mammals. Brain Res Bull 57:765-775.

Gould E, Gross CG (2002) Neurogenesis in adult mammals: some progress and problems. J Neurosci 22:619-623.

Gould E, Beylin A, Tanapat P, Reeves A, Shors TJ (1999a) Learning enhances adult neurogenesis in the hippocampal formation. Nat Neurosci 2:260-265.

-Gould E, Reeves AJ, Graziano MSA, Gross CG (1999b) Neurogenesis in the neocortex of adult primates. Science 286:548-552.

Lois C, Alvarez-Buylla A (1993) Proliferating subventricular zone cells in the adult mammalian forebrain can differentiate into neurons and glia. Proc Natl Acad Sci USA 90: 2074-2077.

Luzzati F, de Marchis S, Fasolo A, Peretto P (2006) Neurogenesis in the caudate nucleus of the adult rabbit. J Neurosci 26:609-621.

Kempermann G, Kuhn HG, Gage FH (1998) Experience-induced neurogenesis in the senescent dentate gyrus. J Neurosci 18:32063212 .
Kolb B, Pedersen B, Ballermann M, Gibb R, Whishaw IQ (1999) Embryonic and postnatal injections of bromodeoxyuridine produce age-dependent morphological and behavioral abnormalities. J Neurosci 19: 2337-2346

Margotta V, Morelli A, Alfei L (2000) PCNA positivity in the telencephalic matrix areas in the adult of a frog, Rana esculenta. Rend Fis Acc Lincei 11:185-196.

Margotta V, Morelli A, Caronti B (2005) Expression of PCNA positivity in the brain of normal adult heterothermic vertebrates: further observations. Ital J Anat Embryol 110:5974.

Marín O, González A, Smeets WJAJ (1997) Basal ganglia organization in amphibians: Afferent connections to the striatum and the nucleus accumens. J Comp Neurol 378:16-49.

-Miller MW, Nowakowski RS (1988) Use of bromodeoxyuridine immunohistochemistry to examine the proliferation, migration and time of origin of cells in the central nervous system. Brain Res 457:44-52.

Minturn J, Geschwind D, Fryer H, Hockfield S (1995) Early postmitotic neurons transiently express TOAD-64, a neural specific protein. J Comp Neurol 355:369-379.

- Mudry KM, Capranica RR (1980) Evoked auditory activity within the telencephalon of the bullfrog (Rana catesbeiana). Brain Res 182: 303-311.

Neary TJ, Northcutt RG (1983) Nuclear organization of the bullfrog diencephalon. J Comp Neurol 213:262-278.

Nieuwenhuys R, Opdam P (1976) Structure of the brain stem. In: Frog Neurobiology (Llinas R, Precht W, eds), pp 811-855. New York: Springer-Verlag.

Northcutt RG, Ronan M (1992) Afferent and efferent connections of the bullfrog medial pallium. Brain Behav Evol 40:1-16.

Nottebohm F (2002) Neuronal replacement in adult brain. Brain Res Bull 57:737-749.

-Olariu A, Cleaver KM, Cameron HA (2007) Decreased neurogenesis in aged rats results from loss of granule cell precursors without lengthening of the cell cycle. J Comp Neurol 501:659-667. 
-Peretto P, Giachino C, Panzica GC, Fasolo A (2001) Sexually dimorphic neurogenesis is topographically matched with the anterior accessory olfactory bulb of the adult rat. Cell Tissue Res 306:385-389.

-Polenov AL, Chetverukhin VK (1993) Ultrastructural radioautographic analysis of neurogenesis in the hypothalamus of the adult frog, Rana temporaria, with special reference to physiological regeneration of the preoptic nucleus. II. Types of neuronal cells produced. Cell Tissue Res 271:351-362.

-Rakic P (2002) Neurogenesis in adult primate neocortex: an evaluation of the evidence. Nature Rev Neurosci 3:65-71.

- Ramirez C, Nacher J, Molowny A, Sánchez-Sánchez F, Irurzun A, López-Garcia C (1997) Photoperiod-temperature and neuroblast proliferation-migration in the adult lizard cortex. NeuroReport 8:2337-2342.

Raymond PA, Easter SS (1983) Postembryonic growth of the optic tectum in goldfish. I. Location of germinal cells and numbers of neurons produced. J Neurosci 3:1077-1091.

-Raucci F, DiFiore MM, Pinelli C, D’Aniello B, Luongo L, Polese G, Radtogi RK (2006) Proliferative activity in the frog brain: A PCNAimmunohistochemistry analysis. J Chem Neuroanat 32:127-142.
Rochefort C, Gheusi G, Vincent JD, Lledo PM (2002) Enriched odor exposure increases the number of newborn neurons in the adult olfactory bulb and improves odor memory. J Neurosci 22:2679-2689.

Rothstein H, van Buskirk RG, Gordon SR, Worgul BV (1975) Seasonal variations in mitosis in the frog: A field study. Experientia 31:939 941.

Schmidt RS (1988) Mating call phonotaxis in female American toads: lesions of central auditory system. Brain Behav Evol 32:119-128.

Sekerková G, Ilijic E, Mugnaini E (2004) Bromodeoxyuridine administered during neurogenesis of the projection neurons causes cerebellar defects in rat. J Comp Neurol 470 221-239.

Simmons AM, Chapman JA, Brown RA (2006) Developmental changes in cell proliferation in the auditory midbrain of the bullfrog, Rana catesbeiana. J Neurobiol 66:12121224 .

Tseng HC, Ruegg SJ, Maronski M, Messam CA Grinspan JB, Dichter MA (2006) Injuring neurons induces neuronal differentiation in a population of hippocampal precursor cells in culture. Neurobiol Dis 22:88-97.
Ueda J, Saito H, Watanabe H, Evers MB (2005) Novel and quantitative DNA dot-blotting method for assessment of in vivo proliferation. Am J Physiol Gastrointest Liver Physiol 288:G842-G847.

Valero J, Weruaga E, Murias AR, Recio JS, Alonso JR (2005) Proliferation markers in the adult rodent brain: Bromodeoxyuridine and proliferating cell nuclear antigen. Brain Res Protoc 15:127-134.

-Walkowiak W, Berlinger M, Schul J, Gerhardt HC (1999) Significance of forebrain structures in acoustically guided behavior in anurans. Eur J Morphol 37:177-181.

Zupanc GKH (2001) Adult neurogenesis and neuronal regeneration in the central nervous system of teleost fish. Brain Behav Evol 58: 250-275.

Zupanc GKH, Horschke I, Ott R, Rascher GB (1996) Postembryonic development of the cerebellum in gymnotiform fish. J Comp Neurol 370:443-464.

Zupanc GKH, Hinsch K, Gage FH (2005) Proliferation, migration, neuronal differentiation, and long-term survival of new cells in the adult zebrafish brain. J Comp Neurol 488: 290-319. 